\title{
Indicadores de pressão-estado-resposta para avaliação da conservação ambiental de riachos urbanos
}

Várias cidades brasileiras se estabeleceram em função de um rio ou de riachos. É o caso de São Paulo, Belém, Manaus, Recife, João Pessoa e tantas outras. O modelo de urbanização higienista aterrou e canalizou rios e riachos, afetando negativamente as suas funções ecológicas e a qualidade de vida das pessoas. Recentemente, os rios e riachos urbanos, em várias cidades do mundo, vêm passando por um processo de revitalização, buscando reestabelecer o seu equilíbrio ecológico e sua função social. Este trabalho sugere um conjunto de indicadores para consolidar de maneira mais efetiva o processo de diagnóstico da situação dos riachos urbanos no Brasil, assim como avaliar a eficácia das intervenções de revitalização nesses ecossistemas. Os indicadores foram pré-selecionados a partir de revisão bibliográfica e posteriormente enviados para a avaliação de especialistas. As respostas do formulário foram submetidas ao teste de confiabilidade de Alfa de Cronbach. O desvio padrão médio das respostas foi de 0,75 , considerando a escala atribuída de 1 a 5 . Foram selecionados nove indicadores e classificados no sistema Pressão-Estado-Resposta (PER). Os indicadores selecionados para a dimensão 'pressão' estão relacionados à intensidade de descarga de poluentes no riacho e o impacto sofrido pela urbanização. Para 'estado' foram selecionados um indicador químico, um físico e um biológico. Na 'resposta', ações da sociedade que diminuem as pressões e melhoram o estado ecológico de um riacho urbano. Os indicadores poderão compor um índice e auxiliar no diagnóstico e avaliação de projetos de revitalização de riachos urbanos.

Palavras-chave: Sistema PER; Indicadores Ambientais; Revitalização de Riachos.

\section{Pressure-state-response indicators for environmental conservation assessment of urban streams}

\begin{abstract}
Several Brazilian cities were established due to a river or streams. This is the case of São Paulo, Belem, Manaus, Recife, João Pessoa and many others. The hygienist urbanization model has landed and channeled rivers and streams, negatively affecting their ecological functions and people's quality of life. Recently, urban rivers and streams in several cities around the world have been undergoing a process of revitalization, seeking to reestablish their ecological balance and social function. This paper suggests a set of indicators to more effectively consolidate the process of diagnosing the situation of urban streams in Brazil, as well as to evaluate the effectiveness of revitalization interventions in these ecosystems. The indicators were pre-selected from the literature review and subsequently sent for expert evaluation. The answers to the form were submitted to Cronbach's alpha reliability test. The average standard deviation of the responses was 0.75 , considering the assigned scale from 1 to 5 . Nine indicators were selected and classified in the Pressure-State-Response (PER) system. The indicators selected for the 'pressure' dimension are related to the intensity of pollutant discharge in the stream and the impact suffered by urbanization. For 'state' were selected a chemical, a physical and a biological indicator. And in the 'response', societal actions that reduce pressures and improve the ecological state of an urban stream. The indicators may compose an index and assist in the diagnosis and evaluation of urban stream revitalization projects.
\end{abstract}

Keywords: PER system; Environmental indicators; Stream Revitalization.

Topic: Engenharia de Recursos Hídricos

Reviewed anonymously in the process of blind peer.
Received: 02/10/2019

Approved: 26/11/2019
José Luís Said Cometti (iD

Universidade Federal de Pernambuco, Brasil

http://lattes.cnpq.br/0179381217133453

http://orcid.org/0000-0003-4193-3125

ilscometti@yahoo.com

Jaime Joaquim Pereira da Silva Cabral (it)

Universidade Federal de Pernambuco, Brasil

http://lattes.cnpq.br/2072476094919725

http://orcid.org/0000-0002-1348-8004

icabral@ufpe.br

Taylse Marielly da Conceição

Centro Universitário Maurício de Nassau, Brasil

http://lattes.cnpq.br/0169484855419224

taylsemarielly19@hotmail.com

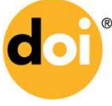

DOI: 10.6008/CBPC2179-6858.2019.006.0017
Referencing this:

COMETTI, J. L. S.; CABRAL, J. J. P. S.; CONCEIÇÃO, T. M.. Indicadores de pressão-estado-resposta para avaliação da conservação ambiental de riachos urbanos. Revista Ibero Americana de Ciências Ambientais, v.10, n.6, p.194-205, 2019. DOI: http://doi.org/10.6008/CBPC2179$\underline{6858.2019 .006 .0017}$ 


\section{INTRODUÇÃO}

O rio é um curso natural de água que se movimenta por meio da gravidade, dos pontos mais altos para os mais baixos do relevo, podendo desaguar em outro rio, em um lago ou no mar. Esses cursos d'água são formados a partir da chuva, do desgelo em picos montanhosos ou do afloramento do lençol freático, dando origem à nascente. Quando um rio desagua em outro, o chamamos de afluente (TUCCl, 2015). Enquanto que os riachos são classificados como rios pequenos com possíveis áreas de inundação em períodos chuvosos (ESTEVES et al., 1999). Dependendo da região do Brasil, os riachos podem ser chamados de córrego (região Sudeste), arroio (região Sul) ou igarapé (região Norte).

Várias cidades brasileiras se estabeleceram em função de um rio ou de riachos. É o caso de São Paulo, Belém, Manaus, Recife, João Pessoa e tantas outras. O rio era utilizado como meio de transporte e favoreceu o crescimento desses centros urbanos (MELO, 2008). Assim, à medida que as cidades se desenvolvem, a ocupação das margens dos cursos d água também avança (REZENDE et al., 2016). O modelo de urbanização higienista, intensificado no Brasil nas décadas de 1950 e 1960, aterrou e canalizou rios e riachos, afetando negativamente as suas funções ecológicas e a qualidade de vida das pessoas (SOUSA et al., 2012).

Pellegrino et al. (2006) acrescenta que a retificação e canalização de riachos com muros de concreto fazem com que a relação entre curso d’água e as margens inundáveis seja interrompida, aumentando a vazão de água e, consequentemente, contribuindo para a ocorrência de enchentes a jusante. Como são áreas mais baixas e susceptíveis a inundações, normalmente são terrenos mais desvalorizados pela indústria imobiliária e mais ocupados por pessoas em situação de vulnerabilidade econômica e que são afetadas pelos impactos (SILVA et al., 2016).

Outro fator de degradação dos riachos em áreas urbanas é o lançamento de resíduos sólidos e de esgoto in natura. A ausência ou precariedade dos sistemas públicos de saneamento nas grandes e pequenas cidades tem ocasionado impactos negativos e, muitas vezes, irreversíveis aos cursos d'água. A matéria orgânica presente nos esgotos, ao ser lançada na água, inicia o processo de decomposição, ocorrendo o consumo do oxigênio dissolvido (OD) da água. Sem OD, os riachos perdem a vida aquática aeróbia, composta por peixes e outros organismos. Além disso, a proliferação de doenças é outro fator preocupante (VON SPERLING, 2014).

Recentemente, os rios e riachos urbanos, em várias cidades do mundo, vêm passando por um processo de revitalização, buscando reestabelecer o seu equilíbrio ecológico e sua função social (BERNHARDT et al., 2007). Nessa ótica, a concepção de parque linear às margens dos cursos d'água é vista como uma alternativa viável, pois traz benefícios ambientais, sociais e econômicos (FRISCHENBRUDER et al., 2006; MARTINEZ, 2016; WHOL et al., 2005). Da mesma forma, é crescente a preocupação sobre a eficácia de projetos de revitalização de rios urbanos (PALMER et al., 2007).

O Urban River Basin Enhancemente Methods (URBEM), financiado pela União Europeia, desenvolveu ferramentas para avaliar o potencial de melhoria e reabilitação de cursos d'água urbanos submetidos a projetos de intervenção (URBEM, 2004). Outros trabalhos sugerem a avaliação da saúde dos rios urbanos por 
meio da integridade biótica ou da qualidade da água, ou por índices compostos por um conjunto de indicadores ambientais, econômicos e sociais (DENG et al., 2014; LADSON, 1999; POMPÊO et al., 2011; TUCCI, 2017; ZHANG et al., 2019). Apesar da disponibilidade de uma longa lista de indicadores ambientais, econômicos e sociais, ainda existem muitas limitações para implementar uma metodologia para avaliar a situação de riachos urbanos no Brasil, principalmente devido à indisponibilidade de dados.

Os indicadores também têm sido utilizados como ferramenta padrão, auxiliando na compreensão das informações sobre fenômenos complexos, em diversos estudos nacionais e internacionais, pois permite medir e avaliar as consequências das atividades antrópicas no ecossistema (DANZ et al., 2005; SILVA et al., 2010; PROBST et al., 2015). São ferramentas essenciais de suporte no processo de tomada de decisão e formulação de políticas ambientais, favorecendo o monitoramento das mudanças do estado da qualidade ambiental ao longo do tempo (GOMES et al., 2012; SHIN et al., 2010).

A Organização para Cooperação e Desenvolvimento Econômico (OCDE) foi uma das organizações pioneiras no desenvolvimento de indicadores ambientais, iniciando um programa específico em 1990 mediante demanda do G-7 em 1989. A OCDE, então, criou o método Pressão-Estado-Resposta (PER) (figura 2.3) como um sistema de indicadores ambientais e de desenvolvimento sustentável (OECD, 2003). Em que 'Pressão' diz respeito às atividades e processos urbanos que produzem mudanças ambientais; 'Estado' refere-se à condição ou qualidade do ambiente; e 'Resposta' são as ações desenvolvidas pela sociedade para prevenir, mitigar ou recuperar o meio afetado. O sistema PER tem sido utilizado em trabalhos com rios urbanos, sendo amplamente recomendado (HUDON et al., 2018; ZHANG et al., 2019).

Portanto, é preciso desenvolver modelos que consigam ser eficazes em simplificar sistemas complexos, como os riachos urbanos, a fim de facilitar o seu entendimento e subsidiar a tomada de decisões, com o uso de indicadores ambientais e sociais. Para tanto, este trabalho sugere um conjunto de indicadores para consolidar de maneira mais efetiva o processo de diagnóstico da situação dos riachos urbanos no Brasil, assim como avaliar a eficácia das intervenções de revitalização nesses ecossistemas.

\section{MATERIAIS E MÉTODOS}

A seleção prévia de indicadores partiu de uma revisão bibliográfica e teve como referência a publicação do URBEM, que define 41 indicadores ambientais, 43 sociais e sete econômicos para avaliação de projetos de intervenção em cursos d'água urbanos (URBEM, 2004) e de outros artigos disponíveis na literatura (DENG et al., 2014; LADSON, 1999; POMPÊO et al., 2011; TUCCI, 2017; ZHANG et al., 2019). Os critérios de seleção foram baseados em Böhringer et al. (2007), sendo eles: simplicidade e clareza, disponibilidade do dado, baixo custo de obtenção e facilidade de aplicação.

Foram pré-selecionados 15 indicadores e construído um questionário Survey (PINSONNEAULT et al., 1993) para avaliar o grau de importância de cada um para avaliar a conservação ambiental de riachos urbanos. O questionário solicitava ao participante, que classificasse o parâmetro em grau de importância em uma escala Likert de 1 a 5 (JOSHI et al., 2015). Também continha um espaço aberto para observações, conforme recomenda Kayo et al. (1997). O questionário foi desenvolvido utilizando a ferramenta Google 
Forms e enviado para especialistas em cursos d'água urbanos com publicações científicas na área. Para validação das respostas, foi submetido o teste de confiabilidade de Alfa de Cronbach (CRONBACH et al., 2004).

O método de PER se baseia no conceito de causalidade, segundo o qual as atividades humanas exercem pressão sobre o ambiente, alterando a qualidade e a quantidade de recursos naturais, ou seja, alterando o seu estado. Dessa forma, a sociedade responde a essas mudanças mediante políticas ambientais, econômicas ou setoriais. É um sistema para monitorar o estado do meio ambiente a partir das relações de causa-feito, incluindo as respostas sociais frente às perturbações produzidas. Os três grupos chaves de indicadores do sistema PER estão descritos a seguir (BAL-DOMANSKA, 2017; NERI et al., 2016; WOLFSLEHNER et al., 2008): a) Pressão - descrevem as pressões exercidas pelas atividades humanas sobre o meio ambiente e sobre os recursos naturais. Entende-se, aqui, por 'pressões' aquelas subjacentes ou indiretas (ou seja, a atividade propriamente dita e as tendências importantes do ponto de vista ambiental), assim como as pressões imediatas ou diretas (ou seja, a utilização de recursos e o lançamento de poluentes e de resíduos). Podem ser traduzidos por indicadores de emissão de contaminantes, eficiência tecnológica, intervenção no território e de impacto ambiental; b) Estado - Referem-se à qualidade do meio ambiente e à qualidade e quantidade dos recursos naturais. Refletem, assim, o objetivo final das políticas ambientais e visam fornecer uma visão geral do estado do meio ambiente e de sua evolução no tempo. À esta categoria pertencem as concentrações de poluentes nos diversos meios, o excesso de cargas críticas, a exposição da população a certos níveis de poluição ou a um ambiente degradado, o estado da fauna e da flora e as reservas de recursos naturais; c) Resposta - avaliam as respostas da sociedade às alterações e preocupações ambientais, bem como a adesão a programas e/ou à implementação de medidas em prol do ambiente; podem ser incluídos neste grupo os indicadores de adesão social, de sensibilização e de atividades de grupos sociais importantes. Eles remetem às ações e reações individuais e coletivas visando: atenuar ou evitar os efeitos negativos das atividades humanas sobre o meio ambiente, ou a isso se adaptar, impor um limite às degradações já infligidas ao meio ambiente ou remediá-las, e conservar e proteger a natureza e os recursos naturais.

Foram selecionados os indicadores avaliados como importante ou muito importante, ou sugeridos por mais de $70 \%$ dos especialistas. Os indicadores foram agrupados de acordo com o sistema Pressão-EstadoResposta (PER), sugerido pela Organization for Economic Cooperation and Development (OECD) para indicadores ambientais (OECD, 2003).

\section{RESULTADOS}

Foram recebidas 52 respostas ao questionário aplicado com especialistas em rios e riachos urbanos de diversas áreas de conhecimento e atuação profissional (Figuras 1a e 1b). A confiabilidade do questionário apresentou um coeficiente Alfa de Cronbach de 0,76, considerado como nível aceitável. O desvio padrão médio das respostas foi de 0,75 , considerando a escala atribuída de 1 a 5 . Os nove indicadores selecionados e classificados no sistema PER podem ser visualizados na Figura 2. A tabela 1 apresenta características dos indicadores selecionados. 

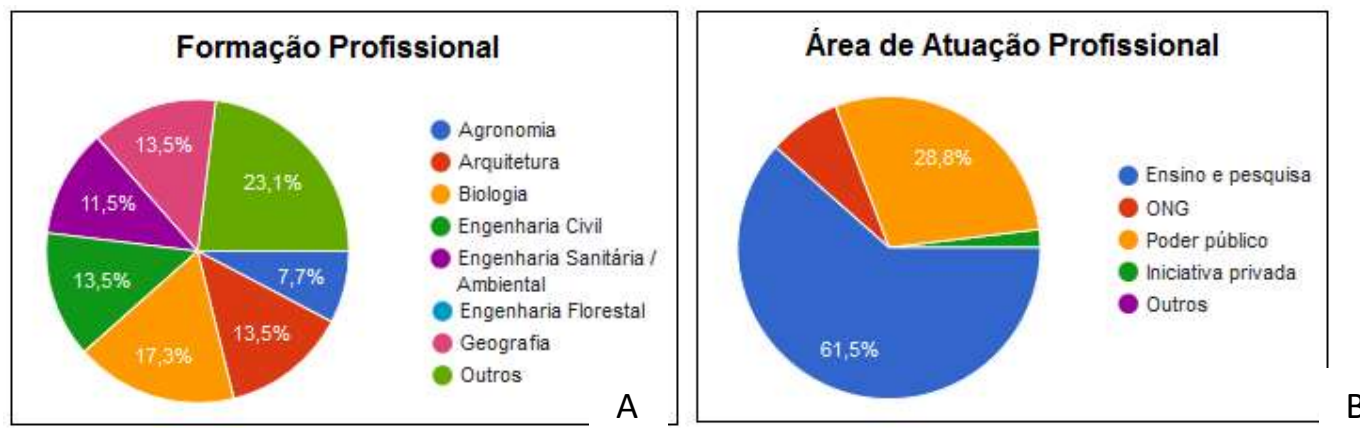

Figura 1a e 1b: Formação e área de atuação profissional dos participantes da pesquisa survey.

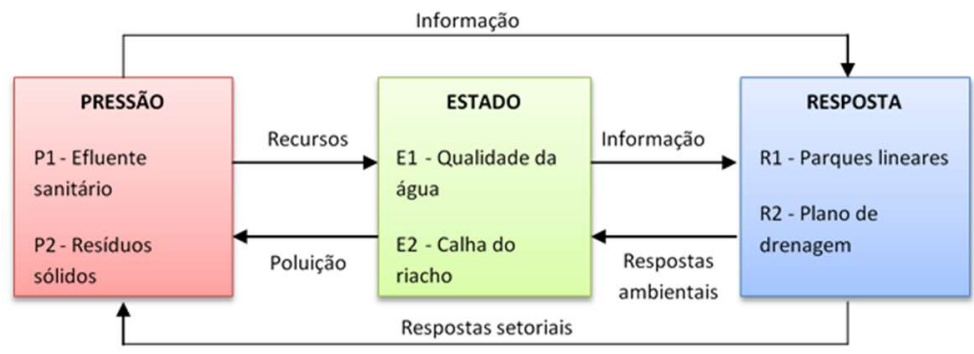

Figura 2: Indicadores agrupados no sistema Pressão-Estado-Resposta para compor o ÍcARU. Fonte: elaborado pelo autor.

Tabela 1: Fórmula de cálculo dos indicadores para avaliar a conservação ambiental de riachos urbanos.

\begin{tabular}{|c|c|c|}
\hline Indicador & Unidade de Medida & Fórmula de Cálculo \\
\hline P1 - Efluente Sanitário & $\%$ & $\begin{array}{l}\qquad C T E=\left(\frac{\text { Col } \times \text { Trat }}{100}\right) \\
\text { Onde: } \\
\text { CTE: \% de coleta e tratamento de esgoto sanitário na área de } \\
\text { drenagem do trecho do riacho ou do município. } \\
\text { Col: \% de coleta de esgoto. } \\
\text { Trat: \% de tratamento de esgoto sanitário em relação ao } \\
\text { coletado. }\end{array}$ \\
\hline P2 - Resíduos Sólidos & $\%$ & $\begin{array}{l}\qquad C D R S=\left(\frac{\text { Col } \times \text { Dest }}{100}\right) \\
\text { Onde: } \\
\text { CDRS: \% de Coleta e tratamento de resíduos sólidos na área } \\
\text { de drenagem do trecho do riacho ou do município. } \\
\text { Col: \% de coleta de resíduos sólidos } \\
\text { Dest: \% de destinação final adequada de resíduos sólidos em } \\
\text { relação ao coletado. }\end{array}$ \\
\hline P3 - Ocupação nas margens & $\%$ & $\begin{array}{l}\qquad O M=\left(\frac{\text { Aocup }}{\text { Atotal }}\right) \times 100 \\
\text { Onde: } \\
\text { OM: \% de ocupação nas margens ou sobre o riacho. } \\
\text { Aocup: Área ocupada na faixa de Área de Preservação } \\
\text { Permanente (APP) ou sobre o riacho. } \\
\text { Atotal: Área total da faixa de APP. }\end{array}$ \\
\hline E1 - Qualidade da água & Escala de 0 a 100 & $\begin{array}{l}\qquad \mathrm{IQA}=\prod_{\mathrm{i}=1}^{\mathrm{n}} \mathrm{qi}{ }^{\mathrm{Wi}} \\
\text { onde: } \\
\text { IQA: Índice de Qualidade de Água } \\
\text { qi: qualidade do i-ésimo parâmetro, um número entre } 0 \text { e } 100 . \\
\text { wi: peso correspondente ao i-ésimo parâmetro, um número } \\
\text { entre } 0 \text { e } 1 \text {, } \\
\text { n: número de variáveis que entram no cálculo. }\end{array}$ \\
\hline E2 - Leito do riacho & Escala de 0 a 25 & $\begin{array}{l}\text { Onde: } \\
\text { PLR: Permeabilidade do leito do riacho } \\
\text { a: fundo; b1 e b2: paredes; } c 1 \text { e } c 2 \text { : taludes }\end{array}$ \\
\hline
\end{tabular}




\begin{tabular}{|c|c|c|}
\hline & & $\begin{array}{l}\text { Para o fundo e paredes: } \\
0 \text { - Revestimento impermeável com secção fechada. } \\
\text { 1- Revestimento impermeável com seção aberta. } \\
2 \text { - Revestimento permeável. } \\
5 \text { - Natural } \\
\text { Para o talude: } \\
0 \text { - Revestimento impermeável. } \\
\text { 2- Revestimento permeável. } \\
3 \text { - Natural sem vegetação. } \\
5 \text { - Natural com vegetação. }\end{array}$ \\
\hline E3 - Vegetação ciliar & $\%$ & $\begin{array}{l}\qquad C V=\left(\frac{A c v}{A t}\right) \times 100 \\
\text { Onde: } \\
C V: \% \text { de cobertura vegetal arbustiva e arbórea na faixa de } \\
\text { APP do trecho do riacho. } \\
\text { Acv: área de cobertura vegetal arbustiva e arbórea na faixa de } \\
\text { APP do trecho do riacho. } \\
\text { At: área total da faixa de APP do trecho do riacho. }\end{array}$ \\
\hline R1 - Parques lineares & $\%$ & $\begin{array}{l}\qquad P L=\left(\frac{A p l}{A t}\right) \times 100 \\
\text { Onde: } \\
\text { PL: \% de área com parque linear*. } \\
\text { Apl: área com parque linear na faixa de APP do trecho do } \\
\text { riacho. } \\
\text { At: área total da faixa de APP do trecho do riacho. }\end{array}$ \\
\hline R2 - Plano de drenagem & Conceito & $\begin{array}{l}\text { Medidas consideradas sustentáveis: } \\
\text { Escala do lote: telhado verde; telhado para captação e } \\
\text { armazenamento de águas pluviais; \% de área permeável. } \\
\text { Espaços públicos: pavimentos permeáveis; poços e } \\
\text { trincheiras de infiltração; jardins de chuva. } \\
\text { Infraestrutura urbana: bacias de retenção; bacias de } \\
\text { detenção; valas de infiltração; tratamento de águas pluviais; } \\
\text { canais naturais; sistemas de previsão e alerta de inundações. }\end{array}$ \\
\hline R3 - Governança participativa & Conceito & $\begin{array}{l}\text { Instrumentos de participação na Governança: Definição de } \\
\text { papéis e responsabilidades de atores sociais; Qualificação da } \\
\text { comunidade para processos de decisão; Consulta pública; } \\
\text { Audiência pública; Conselhos consultivos; Comitês de bacia; } \\
\text { Transparência e publicidade das ações; e Educação ambiental. }\end{array}$ \\
\hline
\end{tabular}

\section{DISCUSSÃO}

O conceito de conservação ambiental de riachos urbanos é um conceito relativo, difuso e dinâmico que pode variar de acordo com os interesses da sociedade. O sistema PER foi incialmente desenvolvido para fornecer apoio à elaboração de políticas públicas ambientais (NERI et al., 2016). Atualmente, esse sistema é usado em vários países para estudar as condições de saúde dos ecossistemas. Por exemplo, Hughey et al. (2004) estudaram as percepções das pessoas sobre o estado do ambiente da Nova Zelândia usando o quadro PER. Levrel et al. (2009) selecionaram indicadores PER para a gestão da biodiversidade em uma reserva da biosfera na França. Souza et al. (2014) utilizaram o modelo PER na avaliação da qualidade das praias no estado da Bahia, Brasil.

Os indicadores da dimensão 'pressão' estão relacionados à intensidade de descarga de poluentes no riacho e o impacto sofrido pela urbanização. Para 'estado' foram selecionados um indicador químico, um físico e um biológico. Na 'resposta', ações da sociedade que diminuem as pressões e melhoram o estado 
ecológico de um riacho urbano. Alguns desses indicadores selecionados também foram utilizados por Zhang et al. (2019), em um sistema PER para o um rio urbano na China.

P1 - Efluente sanitário: O lançamento de esgoto sanitário sem tratamento é apontado com um dos principais fatores de degradação dos recursos hídricos urbanos (WALSH et al., 2005). No Brasil, apenas 58\% do esgoto é coletado e, destes, $73,69 \%$ é tratado (SNIS, 2018). A matéria orgânica lançada nos cursos d'água consome o oxigênio dissolvido, inviabilizando a vida aeróbia, ocasiona outros problemas como a eutrofização, sedimentação de lodo e contaminação por microrganismos patogênicos presente nas fezes humanas.

P2 - Resíduos sólidos: Quando os serviços de coleta de resíduos sólidos urbanos não são eficientes, aliado à baixa consciência ambiental da população, os cursos d'água urbanos acabam sendo utilizados como meio de disposição final. Os resíduos se acumulam nas margens ou no fundo dos rios e córregos, impedem o fluxo da água e contribuem para o aumento das enchentes e inundações (TUCCI, 2015). Podendo, também, contaminar a água e peixes com metais pesados oriundos de pilhas e lâmpadas (BERNHOFT, 2012).

P3 - Ocupação nas margens ou sobre o riacho: Os cursos d'água naturais apresentam as características de continuidade dos escoamentos e de conectividade de habitats. A conexão lateral gerada pela inundação produz uma troca de água, sedimentos, nutrientes e organismos fundamentais para a integridade de ecossistemas fluviais. Por outro lado, as águas, ao extravasarem, dissipam energia cinética na planície de inundação efetuando um trabalho de remodelação dos sedimentos e da vegetação existente nas zonas inundadas (THOMS, 2003; TÁNAGO et al., 2007).

Pellegrino et al. (2006) acrescenta que a retificação e canalização do rio com muros de concreto fazem com que a relação entre rio e as margens inundáveis seja interrompida, aumentando a vazão de água e, consequentemente, contribuindo para a ocorrência de enchentes a jusante. As ocupações edificadas dos mais variados usos, nas margens dos riachos, ou até mesmo sob o seu leito e infraestrutura viária impactam negativamente a conectividade lateral.

E1 - Índice de Qualidade da Água (IQA): O IQA incorpora nove parâmetros (OD, coliformes, pH, DBO, temperatura, nitrogênio, turbidez e sólidos dissolvidos) e pesos específicos considerados relevantes para a avaliação da qualidade das águas (VON SPERLING, 2014). Alguns especialistas apontaram limitações do uso do IQA como, por exemplo, os backgrounds regionais. Entretanto, o uso do IQA é uma tentativa prevista por programas de monitoramento de águas superficiais de vários órgãos ambientais brasileiros, como forma de acompanhar, por meio de informações resumidas, a possível deterioração dos recursos hídricos ao longo da bacia hidrográfica ou ao longo do tempo e fornece resultados de fácil interpretação (VIEIRA et al., 2019; ZSCHORNACK et al., 2018).

E2 - Permeabilidade da calha do riacho: A drenagem tradicional tem transformado os cursos d'água urbanos em grandes galerias de escoamento das águas pluviais. A impermeabilização do canal fluvial ocasiona grandes perdas para o rio, principalmente por impossibilitar a troca entre as águas superficiais e subterrâneas (TUCCI, 2015). Em épocas de cheias, o rio alimenta o lençol freático e na seca ocorre o inverso. A impermeabilização com revestimentos lisos aumenta a velocidade de escoamento das águas e provocam 
erosões a jusante (CARVALHO et al., 2017). Também afeta a biota, pois a ocorrência natural de seixos rolados é responsável pela manutenção do ciclo vital de espécies, principalmente da fauna bentônica. Além disso, a ausência de rugosidade diminui o movimento turbulento e a oxigenação da água (BINDER, 1998). Este indicador é composto por três parâmetros: o revestimento do fundo e das paredes do canal fluvial (leito menor) e dos taludes (leito maior).

E3 - Vegetação ciliar: A vegetação ciliar tem um importante papel ecológico e hidrológico para os cursos d'água. Dentre as funções ecológicas está o hábitat da fauna terrestre e aquática, produção alimentos, cobertura e proteção térmica para peixes e outros animais. Em relação às suas funções hidrológicas, a vegetação retarda o escoamento superficial, promove a estabilidade das margens e mantém nascentes. Além disso, a mata ciliar ainda melhora a qualidade da água por meio da filtragem e retenção de sedimentos e processos de absorção de nutrientes pelas raízes (KAGEYAMA et al., 2001; LAFORTEZZA et al., 2013).

R1 - Parques lineares: Parques lineares, ou greenways, são intervenções urbanísticas construídas ao longo de cursos d'água, projetados e manejados com múltiplos objetivos, entre eles ecológicos, estruturais, recreativos, culturais e estéticos, compatíveis com o uso sustentável do solo. Tais espaços são capazes de conectar áreas verdes e pessoas, proteger e recuperar o ecossistema, controlar enchentes, abrigar práticas de lazer, esporte e cultura, além de contribuir com alternativas não motorizadas de mobilidade urbana (KONDOLF et al., 2017; SOARES et al., 2012; MARTINEZ, 2016).

O parque linear tem sido apontado como um instrumento essencial para integração da paisagem urbana com os cursos d'água. Eles permitem uma interação maior das pessoas com os rios e riachos, promovendo o sentimento de zelo (MACEDO et al., 2011; ÖZGÜNER et al., 2012). Segundo Macedo et al. (2011), a mudança no uso da água de um uso puramente sanitário para outros ligados ao lazer, criando condições estéticas mais favoráveis, promove uma maior integração do corpo d'água com a paisagem e a vida urbana, fazendo com que a população volte a se identificar com o corpo d'água. Projetos de revitalização de rios com áreas de recreação tiveram mais sucesso na Austrália (FINDLAY et al., 2006).

R2 - Plano de Drenagem Urbana Sustentável: Os Sistemas Urbanos de Drenagem Sustentável (SUDS) visam reduzir o impacto da impermeabilização solo nas cidades sobre os hidrogramas de cheias (ROY et al., 2008). Os SUDS priorizam a instalação de dispositivos que retardam a chegada das águas no corpo d'água, resultando na redução da sua vazão de pico (ROY et al., 2008). Um melhor gerenciamento de águas pluviais urbanas na fonte, ou próximo à captação, resulta em diminuição do risco de enchentes e inundações, além de criar 'paisagens verdes' e melhorar o microclima urbano (COUTTS et al., 2013).

As técnicas de manejo sustentável de águas pluviais urbanas são utilizadas em diversos locais ao redor do mundo. Elas são classificadas em estruturais - quando envolve alguma obra de engenharia - e não estruturais - ações políticas e sociais. São aplicadas nas escalas do terreno ou lote, nos espaços públicos, como ruas, avenidas, praças e passeios, e também na infraestrutura urbana como o sistema viário e de micro e macrodrenagem (REIS et al., 2014; TORAN et al., 2017; BOCKHORN et al., 2017).

Poços de infiltração, trincheiras de infiltração, jardins de chuva, pavimentos permeáveis, bacias de retenção são alguns exemplos de aplicação dessa técnica de drenagem, além da revitalização de cursos 
d'água urbanos. Essas técnicas preventivas e compensatórias têm sido apontadas como mais ambientalmente adequadas para o manejo de águas pluviais urbanas e reduzem os impactos ambientais nos corpos hídricos (REIS et al., 2014; TORAN et al., 2017: BOCKHORN et al., 2017). No Brasil não existe uma política pública universalizada para a implementação de SUDS. Entretanto, algumas cidades começaram a incorporá-las nos seus Planos Diretores de Drenagem Urbana (PDDrUr) ou no Plano de Manejo de Águas Pluviais Urbanas (VILLANUEVA et al., 2011).

R3 - Governança Participativa: Governança é a capacidade dos governos de planejar, formular e programar políticas e cumprir funções (FERNANDES et al., 2012; JACOBI, 2012). Atualmente, é incorporada a este conceito a forma pela qual o governo exerce o seu poder. Neste contexto, a governança é um importante instrumento para a participação democrática da população nos Governos (GROTE et al., 2002; HIRST, 2000; KOOIMAN, 2002). Essa 'governança participativa', baseada na interação entre o governo e a sociedade, tende a potencializar as ações político-administrativas e a diminuir resistências e oposições aos projetos políticos de revitalização de rios (BOURDIN, 2001).

De acordo com Palmer et al. (2007), que realizou uma revisão dos projetos de revitalização de rios nos EUA, os projetos que obtiveram melhores resultados foram aqueles onde havia o envolvimento da população residente na bacia referente ao projeto. A importância ainda deve ser dada à heterogeneidade existente dentro dos atores sociais, a fim de garantir que a maior parcela possível da população seja integrada no processo decisório (SEIDL et al., 2013).

Os indicadores têm a capacidade de descrever um estado ou uma resposta dos fenômenos que ocorrem em um meio. Surgem como auxiliadores nas tomadas de decisões, fundamentando as argumentações mediante o fornecimento das informações dos processos. O relevante é que o indicador seja um instrumento que permita a percepção, por meio de um valor, de dado fenômeno ou de uma condição de modo simplificado, compreensível e comparável.

Os indicadores também têm sido utilizados como ferramenta padrão, auxiliando na compreensão das informações sobre fenômenos complexos, em diversos estudos nacionais e internacionais, pois permite medir e avaliar as consequências das atividades antrópicas no ecossistema (DANZ et al., 2005; SILVA et al., 2010; PROBST et al., 2015). São ferramentas essenciais de suporte no processo de tomada de decisão e formulação de políticas ambientais, favorecendo o monitoramento das mudanças do estado da qualidade ambiental ao longo do tempo (GOMES et al., 2012; SHIN et al., 2010).

Entretanto, os indicadores não são a solução para qualquer análise, dada a complexidade e incerteza dos ecossistemas. Eles apenas cumprem com sua função de simplesmente indicarem os caminhos para avaliação, para a discussão e para a percepção do ambiente, cabendo a quem os utiliza realizar as demais etapas. Portanto, um indicador ou um sistema de indicadores devem ser cuidadosamente selecionados pela sua capacidade de medir o que se pretende, por sua confiabilidade e por sua capacidade de reproduzir os mesmos resultados quando aplicados em condições similares. 


\section{CONCLUSÕES}

Riachos urbanos são ecossistemas complexos e dinâmicos que estabelecem conectividades com outros sistemas naturais, urbanos e sociais. São ambientes que, historicamente, sofrem degradação com o estrangulamento e impermeabilização do seu leito, supressão da vegetação ciliar e disposição inadequada de efluentes e resíduos sólidos. A recuperação dos serviços ambientais e sociais de rios e riachos urbanos tem sido uma tendência mundial na tentativa de tornar as cidades mais sustentáveis. Existem vários casos em cidades na Europa, Estados Unidos, Ásia e também no Brasil.

O modelo Pressão-Estado-Resposta (PER) é o marco ordenador mais utilizado na análise de indicadores da área ambiental e do Desenvolvimento Sustentável. A classificação dos indicadores no sistema PER neste trabalho apresentou de forma bastante clara, nos casos estudados, a compreensão do que está acontecendo com o ecossistema (Estado), os causadores de degradação ambiental (Pressão) e como a sociedade está agindo a respeito (Resposta). O método PER se mostrou adequado para avaliar a conservação de riachos urbanos.

Portanto, é necessário que a complexidade das variáveis ambientais e sociais pertinentes aos riachos urbanos, seja modelada e traduzida em expressões linguísticas de fácil compreensão pelos diversos atores sociais. Torna-se relevante estabelecer um índice de conservação ambiental de riachos urbanos, a partir dos indicadores selecionados e classificados no sistema PER, para mostrar de forma clara o diagnóstico do ambiente, orientar o processo de tomada de decisão e subsidiar a elaboração de políticas públicas que visem a revitalização e conservação de riachos urbanos.

\section{REFERÊNCIAS}

BAL-DOMANSKA, B.. Spatial-Temporal Analysis of Selected Socio-Economic Problems Related to Sustainable Development in the Pressure-State-Response Framework. Folia Oeconomica, v.2, n.328, p.92-110, 2017. DOI: http://dx.doi.org/10.18778/0208-6018.328.06

BERNHARDT, E. S.; PALMER, M. A.. Restoring streams in an urbanizing world. Freshwater Biology, v.42, n.4, p.738-741, 2007.

BERNHOFT, R. A.. Mercury toxicity and treatment: a review of the literature. Journal of Environmental and Public Health, v.2012, n.2012, p.10. DOI: http://dx.doi.org/10.1155/2012/460508

BINDER, W.. Rios e Córregos, Preservar - Conservar Renaturalizar: A Recuperação de Rios. Possibilidades e Limites da Engenharia Ambiental. Rio de Janeiro: SEMADS, 1998.

BOCKHORN, B.; KLINT, K. E. S.; LOCATELLI, L.; PARK, Y.-J.; BINNIN. P. J.; SUDICKY, E.; JENSEN, M. B.. Factors Affecting the Hydraulic Performance of Infiltration Based SUDS in Clay. Urban Water Journal, v. 14, n. 2, p. 125-133, 2017.

BÖHRINGER, C.; JOCHEM, P. E. P.. Measuring the immeasurable - a survey of sustainability indices. Ecological Economics, v.63, p.1-8, 2007.
BOURDIN, A.. A questão local. Rio de Janeiro: DP\&A, 2001.

CARVALHO, A. T. F.; SILVA, O. G.; CABRAL, J. J. S. P.. Efeitos do revestimento de canal e impermeabilização do solo à dinâmica de inundação do rio Arrombados-PE. Geociências, v.36, n.1, p. 6-88, 2017.

COUTTS, A. M.; DALY, E.; BERINGER, J.; TAPPER, N. J.. Assessing practical measures to reduce urban heat: Green and cool roofs. Building and Environment, v.70, p.266-276, 2013. DOI:

http://dx.doi.org/10.1016/i.buildenv.2013.08.021

CRONBACH, L. J.; SHAVELSON, R. J.. My current thoughts on coefficient alpha and successor procedures. Educational and Psychological Measurement, v.64, n.3, p.391-418, 2004.

DANZ, N. P.; REGAL, R. R.; NIEMO, G. J.; BRADY, V. J.. Environmentally stratified sampling design for the development of great lakes environmental indicators. Environmental Monitoring and Assessment, New York, v.102, n.1-3, p.41-65, 2005.

DENG, X. J. et al. Establishment and application of the index system for urban river health assessment. Acta Ecol. Sin, v.34, p.993-1001, 2014. 
ESTEVES, K. E.; ARANHA, J. M. R.. Ecologia trófica de peixes de riachos. In: CARAMASCHI, E. P.; MAZZONI, R.; PERESNETO, P. R.. Ecologia de peixes de riachos. Série Oecologia Brasiliensis. Rio de Janeiro, 1999. p.157-182.

FERNANDES, B. M.; WELCH, C. A.; GONÇALVES, E. C.. Land Governance in Brazil: A geo-historical review. International Land Coalition, Rome, n.2, p.62, 2012.

FINDLAY, S. J.; TAYLOR, M. P.. Why rehabilitate urban river systems?. Area, v.38, n.3, p.312-325, 2006.

FRISCHENBRUDER, M. T. M.; PELLEGRINO, P.. Using greenways to reclaim nature in Brazilian cities. Landscape and Urban Planning, n.76, p.67-78, 2006. DOI: http://doi.org.10.1016/j.landurbplan.2004.09.043

GOMES, P. R; MALHEIROS, T. F.. Proposta de análise de indicadores ambientais para apoio na discussão da sustentabilidade. Revista Brasileira de Gestão e Desenvolvimento Regional, Taubaté, v.8, n.2, p.151-169, 2012.

GROTE, J. R.; GBIKPI, B.. Participatory governance. Political and societal implications. Opladen: Leske + Budrich, 2002.

HIRST, P.. Democracy and governance. In: PIERRE, J.. Debating governance: authority, steering and democracy. New York: Oxford University Press, 2000. p.13-35.

HUDON, C; JEAN, M.; LÉTOURNEAU, G.. Temporal (19702016) changes in human pressures and wetland response in the St. Lawrence River (Québec, Canada). Science of the Total Environment, n.643, p.1137-1151, 2018. DOI: https://doi.org/10.1016/j.scitotenv.2018.06.080

HUGHEY, K. F. D.; CULLEN, R.; KERR, G. N.; COOK, A. J.. Application of the pressure-state-response framework to perceptions reporting of the state of the New Zealand environment. J. Environ. Manag., v.70, p.85-93, 2004. DOI: https://doi.org/10.1016/j.jenvman.2003.09.020

JACOBI, P. R.. Governança ambiental, participação social e educação para a sustentabilidade. In: PHILIPPI, A. et al. Gestão da natureza pública e sustentabilidade. Barueri: Manole, 2012. p.343-361.

JOSHI, A.; KALE, S.; CHANDEL, S.; PAL, D. K.. Likert scale: explored and explained. Br. J. App. Sci. Technol, n.7, p.396403, 2015. DOI: http://doi.org.10.9734/BJAST/2015/14975

KAGEYAMA, P. Y.; GANDARA, F. B.. Recuperação de áreas ciliares. In: RODRIGUES, R. R.; LEITÃO FILHO, H. F... Matas ciliares: conservação e recuperação. 2 ed. São Paulo: EDUSP, 2001. p.249-270.

KAYO, E. K.; SECURATO, J. R.. Método Delphi: fundamentos, críticas e vieses. Cadernos de Pesquisa em Administração, v.1, n.4, p.51-61, 1997.

KONDOLF, G. M.; PINTO, P. J.. The social connectivity of urban rivers. Geomorphology, v.277, p.182-196, 2017. DOI: http://doi.org/10.1016/i.geomorph.2016.09.028

KOOIMAN, J. G.. A social-political perspective. In: GROTE, J. R; GBIKPI, B.. Participatory governance. Political and societal implications. Opladen: Leske + Budrich, 2002. p.71-96.
LADSON, A. R.. Development and testing of an Index of Stream Condition for waterway management in Australia. Freshw. Biol., v.41, p.453-468, 1999. DOI: http://dx.doi.org/10.1046/j.1365-2427.1999.00442

LAFORTEZZA, R.; DAVIES, C.; SANESI, G.; VAN DEN BOSCH, C. K.. Green infrastructure as a tool to support spatial planning in European urban regions. Journal of Biogeosciences and Forestry, v.6, p.102-108, 2013.

LEVREL, H.; KERBIRIOU, C.; COUVET, D.; WEBER, J.. OECD pressure-state-response indicators for managing biodiversity: A realistic perspective for a French biosphere reserve. Biodivers. Conserv., v.18, p.1719-1732, 2009. DOI: http://dx.doi.org/10.1007/s10531-008-9507-0

MACEDO, D. R.; MAGALHÃES, A. P.. Percepção Social no Programa de Restauração de cursos d'água urbanos em Belo Horizonte. Sociedade \& Natureza, v.23, n.1, p.51-63, 2011.

MARTÍNEZ, P. C.. El árbol en el ecosistema urbano: relaciones entre nuevo urbanismo, sociedad y gestión racional del riesgo. Ing. Univ., Bogotá, v.20, n.1, 2016. DOI: http://dx.doi.org/10.11144/Javeriana.iyu20-1.tuec

MELLO, S. S.. Na beira do rio tem uma cidade: Urbanidade e valorização dos corpos d'água. Tese (Doutorado em Arquitetura e Urbanismo) - Universidade de Brasília, 2008.

NERI, A. C.; DUPIN, P.; SANCHEZ, L. E.. A pressure-stateresponse approach to cumulative impact assessment. J. Clean. Prod., v.126, p288-298, 2016. DOI: https://doi.org/10.1016/j.jclepro.2016.02.134

OECD. Organisation for Economic Co-operation and Development. Environmental Indicators. Development, Measurement and Use - Reference Paper. OECD, 2003.

ÖZGÜNER, H.; ERASLAN, S.; YILMAZ, S.. Public perception of landscape restoration along a degraded urban streamside. Land Degradation and Development, v.23, p.24-33, 2012.

PALMER, M. A.; BERNHARDT, E. S.; SUDDUTH, E. B.; ALLAN J. D.. Restoring Rivers One Reach at a Time: Results from a Survey of U.S. River Restoration Practitioners. Restoration Ecology, v.15, n.3, p.482-493, 2007.

PELLEGRINO, P. R. M.; GUEDES, P. P.; PIRILLO, F. C.; FERNANDES, S. A.. A paisagem da borda: uma estratégia para a condução das águas, da biodiversidade e das pessoas. In: COSTA, L. M. S. A.. Rios e Paisagens Urbanas em Cidades Brasileiras. Rio de Janeiro: Viana e Mosley, 2006.

PINSONNEAULT, A.; KRAEMER, K. L.. Survey research in management information systems: an assessement. Journal of Management Information System, v.10, p.75-105, 1993. DOI: http://doi.org.10.1080/07421222.1993.11518001

POMPÊO, C. A.; RIGOTTI, J. A.; FREITAS FILHO, M. D.. Urban stream condition Assessment. In: INTERNATIONAL CONFERENCE ON URBAN DRAINAGE, 12. Anais. Porto Alegre, 2011.

PROBST, W. N.; STELZENMULLER, V.. A benchmarking and assessment framework to operationalise ecological indicators based on time series analysis. Ecological 
Indicators, v.55, p.94-106, 2015. DOI: http://doi.org/10.1016/i.ecolind.2015.02.035

REIS, R. P. A.; ILHA, M. S. O.. Comparação de Desempenho Hidrológico de Sistemas de Infiltração de Água de Chuva: poço de infiltração e jardim de chuva. Ambiente Construído, v.14, n.2, p.79-90, 2014

REZENDE, G. B. M.; ARAÚJO, S. M. S.. As cidades e as águas: ocupações urbanas nas margens de rios. Revista de Geografia, Recife, v.33, n.2, p.119-135, 2016.

ROY, A. H.; WENGER, S. J.; FLETCHER, T. D.; WALSH, C. J.; LADSON, A. R.; SHUSTER, W. D.; THURSTON, H. W.; BROWN R. R.. Impediments and solutions to sustainable, watershedscale urban stormwater management: lessons from Australia and the United States. Environmental Management, v.42, n.2, p.344-359, 2008.

SEIDL, R.; STAUFFACHER, M.. Evaluation of river restorationby local residents. Water Resources Research, v.49, p. 077-7087, 2013. DOI: http://dx.doi.org/10.1002/2013WR013988

SHINY. J.; SHANNON, L. J.. Using indicators for evaluating, comparing, and communicating the ecological status of exploited marine ecosystems. The Indi Seas project, ICES. Journal of Marine Science, v.67, p.686-691, 2010.

SNIS. Sistema Nacional de Informações sobre Saneamento. Diagnóstico dos Serviços de Água e Esgotos. Brasília: SNSA, 2017.

SILVA, A. M.; CORREIA, A. M. M.; CÂNDIDO, G. A.. Ecological Footprint Method: Avaliação da Sustentabilidade no Município de João Pessoa, PB. In: CÂNDIDO, G. A.. Desenvolvimento Sustentável e Sistemas de Indicadores de Sustentabilidade: Formas de aplicações em contextos geográficos diversos e contingências específicas. Campina Grande: UFCG, 2010. p.236-271.

SILVA, M. M. N.; LIMA, D. F.; SOUZA JUNIOR, A. M.; CARVALHO, C. C. A.. Segregação socioespacial: os impactos das desigualdades sociais frente a formação e ocupação do espaço urbano. Revista Monografias Ambientais, v.15, n.1, p.256-263, 2016. DOI: http://doi.org.10.5902/22361308

SOARES, M. C.; BONZI, R. S.; OLIVEIRA, E. M.. Aplicação do Desenho Ambiental na Bacia do Córrego das Corulas: potencialidades e limitações na implantação de um parque linear. Revista LABVERDE, v.4, p.30-62, 2012.

SOUSA, C. F.; CRUZ, M. A. S.; TUCCI, C. E. M..

Desenvolvimento urbano debaixo impacto: planejamento e tecnologias verdes para a sustentabilidade das águas urbanas. Revista Brasileira de Recursos Hídricos, v.17, p.918, 2012.

SOUZA, J. L.; SILVA, I. R.. Utilização do modelo pressãoestado-resposta na avaliação da qualidade das praias da Ilha de Itaparica, Bahia. Caderno de Geociências, Salvador, v.11, n.1-2, p.103-113, 2014.

TÁNAGO, M. G.; JALÓN, D. G.. Restauración de Ríos. Madrid: Ministerio de Medio Ambiente, 2007.

THOMS, M. C.. Flood-plain river ecosystems: lateral connections and the implications of human interference. Geomorphology, v.56, p.335-349, 2003.

TORAN, L.; JEDRZEJCZYK, C.. Water Level Monitoring to Assess the Effectiveness of Stormwater Infiltration Trenches. Environmental \& Engineering Geoscience, v.23, n.2, p.113124, 2017. DOI: http://doi.org.10.2113/gseegeosci.23.2.113

TUCCI, C. E. M.. Hidrologia Ciência e Aplicação. 4 ed. Porto Alegre: UFRGS, 2015.

TUCCI, C. E. M.. Indicador de Sustentabilidade Hídrica Urbana. REGA, v.14, n.7, 2017. DOI:

http://doi.org.10.21168/rega

URBEM. Urban River Basin Enhancement Methods. New techniques for urban river rehabilitation: How to renaturalise flow regimes Recommendations. 8 ed. 2004.

VIEIRA, B. M.; NADALETI, W. C.; VALENTINI, M. H. K.; SANTOS, G.; VIANA, F. V.; CORRÊA, M, G.. Avaliação e comparação da qualidade das águas entre o canal São Gonçalo e a Lagoa Mirim. Revista Ibero-Americana de Ciências Ambientais. v.10, n.2, p.185-196, 2019. DOI: http://doi.org/10.6008/CBPC2179-6858.2019.002.0016

VILLANUEVA, A. O. N. et al. Gestão da drenagem urbana, da formulação à implementação. REGA, v.8, n.1, p.5-18, 2011. DOI: http://doi.org/10.21168/rega

VON SPERLING, M.. Introdução à Qualidade das Águas e ao Tratamento de Esgotos. 4 ed. Belo Horizonte: UFMG, 2014.

WALSH, C. J.; ROY, A. H.; FEMINELLA, J. W.; COTTINGHAM, P. D.; GROFFMAN, P. M.; MORGAN, R. P.. The urban stream syndrome: current knowledge and the search for a cure. Journal of the North American Benthological Society, v.24, n.3, p.706-723, 2005.

WHOL, E.; ANGEMEIER, P. L.; KONDOLF, G.; BLEDSOE, B. MACDONEEL, L.; MERRIT, D. M.; PALMER, M. A.; POFF, N. L.; TARBOTON, D.. River Restoration. Water Resources Research, v.41, p.1-12, 2005. DOI: https://doi.org/10.1029/2005WR003985

ZHANG, K.; SHEN, J.; HAN, H.; JIA, Y.. Urban River Health Analysis of the Jialu River in Zhengzhou City Using the Improved Fuzzy Matter-Element Extension Model. Water, v.11, n.1190, 2019. DOI: http://doi.org/10.3390/w11061190

ZSCHORNACK, T.; OLIVEIRA, T. M. N.. Avaliação do impacto da implantação do sistema de esgotamento sanitário na qualidade da água da Bacia Hidrográfica do Rio Cachoeira, em Joinville, Santa Catarina. Revista DAE, v.66, n.212, p.118131, 2018. DOI: http://doi.org/10.4322/dae.2018.027

A CBPC - Companhia Brasileira de Produção Científica (CNPJ: 11.221.422/0001-03) detém os direitos materiais desta publicação. Os direitos referem-se à publicação do trabalho em qualquer parte do mundo, incluindo os direitos às renovações, expansões e disseminações da contribuiç̃o, bem como outros direitos subsidiários. Todos os trabalhos publicados eletronicamente poderão posteriormente ser publicados em coletâneas impressas sob coordenação da Sustenere Publishing, da Companhia Brasileira de Produção Científica e seus parceiros autorizados. Os (as) autores (as)

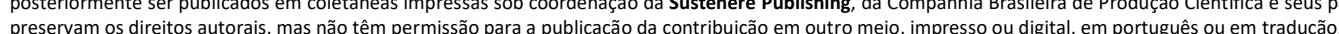

